\title{
Teoría y polémica ${ }^{\mathrm{A}}$
}

A propósito del libro Colombia y la economía mundial, 1830-1910 de José Antonio Ocampo (Bogotá: Fedesarrollo/Siglo XXI, 1984).

\section{Germán Colmenares}

Dar cuenta del libro de José Antonio Ocampo obliga a una referencia explícita de [sic] las objeciones de Salomón Kalmanovitz (v. "Comercio y desarrollo económico durante el siglo XIX”, en Magazín Dominical de El Espectador, n. ${ }^{\circ}$ 107, abril 14 de 1985). No hacerlo conduciría simplemente a referencias oblicuas o a enturbiar un debate puramente intelectual. No veo, por ejemplo, la utilidad o la justeza de las filiaciones intelectuales con las que S. Kalmanovitz introduce sus críticas. Estos procedimientos genealógicos parecen estar destinados exclusivamente a determinar el camino de los réprobos y la senda estrecha de los elegidos. Hoy, sin embargo, las filiaciones intelectuales son un tejido demasiado denso como para atribuirles un transfondo ideológico o buscar en ellas la pureza de una ortodoxia. Hace unos diez años estos intentos de pureza eran una cualidad moral aclamada en las universidades públicas. Hoy existen mayores dosis de escepticismo y tolerancia.

El libro de J. A. Ocampo no se presta tampoco para lo que Malcolm Deas llamó graciosamente la "Mcgreviada", para aludir a una encerrona académica organizada por espíritus piadosos al autor [William Paul McGreevey] de la penúltima síntesis de historia económica colombiana. La razón estriba en el trabajo cuidadoso sobre fuentes y estadística que apoyan los últimos capítulos del libro. La crítica de S. Kalmanovitz se concentra en realidad sobre el capítulo de síntesis inicial y, para el resto

A No tenemos noticia de ninguna publicación de estas páginas de Colmenares. Disponemos de una copia en máquina, que reproducimos íntegramente porque consideramos esas páginas de alto interés. En el texto el autor explica de manera clara el interés y el propósito de sus observaciones, en torno a la obra de un amigo al que respetaba mucho como analista, y a la crítica de esa obra realizada por otro de sus amigos, altamente apreciado también por el autor. Notable en estas páginas la forma como Colmenares elude toda argumentación ad hominem y se dirige a los núcleos argumentales sin consideración de ningún otro tipo, un hecho normal en el campo de la polémica de raíces ilustradas, que no tendría por qué ser considerado un mérito especial. Pero un hecho menos frecuente de lo que podría pensarse en la vida intelectual de un país en el que la amistad de la que se esperan réditos, la servidumbre arribista, el falso colegaje, y deformaciones intelectuales similares son tan frecuentes; un país en el que la vida de las ideas no se asocia ni con la sinceridad, que se piensa que choca con los buenos modales, ni con los criterios racionales de la discusión de argumentos, y en donde la crítica intelectual se piensa bajo figuras patológicas bien condensadas en la frase "dar madera" o, como escuché decir en el Valle del Cauca, "dar sopa y seco"- -alguien me aclaró que en otros lugares de Colombia el uso también es frecuente- - dos expresiones que muestran la dificultad de separar en la vida intelectual un argumento de su expositor, y la tendencia a considerar la crítica intelectual como destrucción de un rival. Una tentación que Colmenares parece detectar en las palabras del crítico, como lo señala con amabilidad y sin excesos, y sin dejar de sopesar con cuidado sus argumentos. 
de los capítulos, reconoce brevemente el rigor y hasta "la claridad y profundidad teóricas". ¿Quiere esto decir que la visión global no tiene nada que ver con el resto del libro?

Aquí hay un problema interesante sobre la construcción del libro, y probablemente la ocasión para profundizar en un debate metodológico. La visión global del capítulo I es un producto posterior a todas las elaboraciones de los capítulos restantes, que tienen un contenido más empírico. Luis Ospina Vásquez observaba cómo una de las mayores dificultades con las que tropieza el autor de una síntesis de historia económica en Colombia es la ausencia de trabajos monográficos sobre una multitud de aspectos. Esta dificultad hoy parece apenas relativa. La división del trabajo historiográfico ha dejado de fundarse en la labor de aquellos que realizan monografías (científicos o algo parecido) y aquellos que exponen los resultados finales en una síntesis graciosa y amena (historiadores o periodistas). El trabajo monográfico se desarrolla, como en el caso de estos capítulos en el libro de J. A. Ocampo, con el objeto de sustentar una síntesis. La elección del tema monográfico no obedece al azar. Hace parte de una estrategia investigativa. Por ejemplo, la comprobación empírica sobre las variaciones de los términos de intercambio a lo largo del siglo debía excluir un tipo de interpretaciones (o de prejuicios) para dar cabida a otras.

Kalmanovitz reprocha a Ocampo el que "haya escogido como eje de su trabajo el comercio exterior”. La crítica parece un poco injusta dados los esfuerzos de Ocampo por describir las maneras de producir en Colombia en el curso del siglo XIX. Este análisis, muy rico en sugerencias, lo conduce a una pequeña obra maestra de percepción histórica, cuando describe lo que él llama producción-especulación. La forma más cruda de esta producción-especulación consistiría en acceder de manera más o menos inmediata a un recurso ofrecido espontáneamente por la naturaleza y aprovechar su condición de rareza o escasez en el mercado internacional.

Creo que esta actitud hunde sus raíces profundas en un medio cultural. Por ejemplo, en las Relaciones de Mando los últimos virreyes ilustrados nos hablan de sus esfuerzos por promover las exportaciones del palo brasil, del dividivi, de la quina, etc. Pero no dejan de observar también que el hombre americano, a diferencia del europeo, confiaba más en lo que le brindaba espontáneamente la naturaleza que en el arte (o texné), lo que los hombres del siglo XVIII llamaban "los frutos del ingenio". ¿Y qué era en últimas la Expedición Botánica sino un inventario de recursos coloniales, de producto raros, cuyo verdadero valor solo podía alcanzarse allí donde podía dárseles un uso adecuado, en la "civilización"? El aspecto utilitario de la empresa científica encontraba así una analogía pronunciada con el descubrimiento de una mina de oro. Por esto la explicación de Ocampo abre todo un terreno para la historia cultural o el estudio de los valores de una sociedad.

Que estas prácticas de raigambre colonial encontraran un mercado propicio y coyunturas favorables en el crecimiento y expansión capitalista de los países europeos 
no tiene nada de extraño. ¿Por qué hablar entonces de "extrañas leyes de la competencia internacional" como si se tratara de un Deus ex machina de la explicación? Ocampo se ha limitado a comprobar que algunos productos exóticos se benefician de un mercado en desequilibrio. Por esta misma razón los europeos buscaban todavía colonias en pleno siglo XIX. Tal vez haya que entender el concepto de desequilibrio en el mercado de estos productos como una noción descriptiva de los efectos de la afición, la moda, la escasez o el exotismo. No veo en esto nada de extraño, a menos que haya dejado de percibir algún aroma insidioso en el azufre de Ocampo.

Uno podría sugerir con humildad que el trabajo del historiador no consiste, como invitaba a practicarlo S. Kalmanovitz, en "jerarquizar adecuadamente las relaciones entre circulación y producción". Este tipo de reflexión y de ortodoxia linda demasiado con la especulación sobre las causas primeras o motor inmóvil y las causas segundas, etc. El historiador se contenta con jerarquizar un material empírico disponible de tal manera de encontrar la solución más razonable (muchas veces provisional) a un problema.

Naturalmente, el problema central del libro de Ocampo, como el de las reflexiones de Kalmanovitz, será objeto siempre de respuestas tentativas. Pues se trata nada menos que de encontrar las claves del atraso colombiano. No creo que este problema tenga una respuesta única o que esta respuesta debe provenir exclusivamente de la historia económica. Aquí uno tiene que admitir que la sugerencia de Kalmanovitz de buscar esta clave en "la propia organización social y regional de la producción" es correcta, y no lo es por el hecho de que se apoye en el fundamentalismo, marxista o de otro tipo. Un humanismo más bien tradicional podría dar una respuesta parecida al observar que el atraso es una función de una sociedad en la que impera la inequidad.

Pero la manera como los productos agrícolas que producía el país, en las condiciones cuidadosamente señaladas por Ocampo, accedieron a los mercados internacionales (¿qué diferencia reveladora habrá entre "la economía exportadora se insertó en el mercado mundial" y "la economía exportadora se articuló al mercado mundial? Introduzco, deliberadamente la variante "accedió" para asegurar que no estoy utilizando una contraseña) es una circunstancia objetiva y además con una ventaja respecto a las leyes que, según S. Kalmanovitz, el "fundamentalismo marxista" descubre en el funcionamiento de las unidades productivas. Mientras que poseemos cifras relativamente confiables para el comercio exterior, toda aproximación a la economía de la hacienda o a su complemento, las economías parcelarias, ha tenido que ser hasta ahora forzosamente descriptiva.

En el terreno de la economía de las haciendas y de las economías campesinas estamos lejos de comprobaciones empíricas rigurosas. A la observación más o menos superficial de lo que ocurría se suele superponer un esquema teórico u otro, generalmente entresacados de otro contexto, sea europeo, asiático o latinoamericano. Por eso todavía existen confusiones sobre el carácter de las regiones, sobre sus unidades pro- 
ductivas o sobre el régimen de su producción. Ahora bien, si ni siquiera poseemos un mapa aproximado de poblamientos (el inicio afortunado está en la obra no traducida todavía de Catherine LeGrand), ¿cómo podría calcularse la proporción del producto que circulaba mercantilmente, tal como parece exigirlo el rigor teórico del fundamentalismo?

Al iniciar su nota el mismo S. Kalmanovitz enlaza un "pensar económico propio" con aquellos trabajos que han explorado la realidad económica de una manera empírica adecuada. Por esto uno se pregunta en dónde reside, en fin de cuentas, la divergencia entre la "posición teórica correcta" (o entre el terrorismo teórico) y el pecado intelectual que se atribuye a Ocampo. Oigamos a Salomón Kalmanovitz: “... yo sostengo que la burguesía y el capitalismo surgen del desarrollo impulsado por la economía parcelaria y su exitosa inserción en el mercado mundial y que las relaciones serviles son debilitadas por las luchas sociales de las clases dominadas y por el mismo desarrollo espontáneo de la acumulación de capital". Si le quitamos a este párrafo un cierto acento épico, su afirmación básica no resulta tan diferente a la admisión de J. A. Ocampo de que "Un modelo diferente surgió en las primeras décadas del siglo XX, sobre la base de una economía parcelaria cafetera. Esta nueva forma de expansión tuvo características radicalmente diferentes a la producción especulación y permitió una acelerada transición al capitalismo en Colombia" (pp. 63-64).

Es posible que la omisión sobre las luchas sociales resulte inadmisible como punto cardinal de doctrina, aunque de este pecado haya que considerar una indulgencia plenaria para los economistas, para los cuales este punto no reviste demasiada pertinencia. Para un historiador, sin embargo, el problema de cómo se daban las luchas sociales no es una mera cuestión teórica. La rebeldía contra el orden inflexible impuesto por la hacienda tenía una salida lógica en los desplazamientos hacia las regiones bajas. Era aquí donde debía producirse el conflicto entre colonizadores espontáneos y aquellos que anulaban sus esfuerzos con un título de propiedad emanado del Estado. En estas regiones se desarrollaron los capítulos de la economía exportadora.

Puede verse entonces cómo el esfuerzo colonizador fue uncido a este otro tipo de desarrollo y que la aspiración libertaria fue transformada en un factor de desarrollo capitalista. Esto al menos es lo que sugiere el trabajo de C. LeGrand. Pero todavía queda mucho por comprobar, examinando uno a uno los desplazamientos hacia zonas de frontera agraria para ver si en medio de ellos surgían haciendas o cómo convivían haciendas y economías parcelarias campesinas.

Por el momento, la síntesis que esboza Ocampo (pp. 67-68) de estas relaciones en diferentes regiones del país es bastante ilustrativa del problema. Si en vez de desarrollar un cuidadoso trabajo empírico sobre los productos de exportación y sobre los problemas de una economía exportadora el énfasis se hubiera puesto en el problema de los excedentes comerciables de la hacienda, la autonomía de las formas parcelarias o la liberación de las formas serviles, es indudable que tendríamos un libro comple- 
tamente diferente. El ángulo de observación se habría desplazado de problemas y causaciones exógenas a sus equivalentes endógenos, pero no por ello la investigación histórica sería más "correcta". Los esfuerzos teóricos, por felices que sean, no dan respuestas históricas. A lo sumo pueden sugerir caminos para la investigación, cambios de énfasis o de perspectiva a partir de los cuales nuestra visión de los accidentes históricos sea mucho más amplia y rica.

\section{Germán Colmenares}

Profesor titular

\section{Universidad del Valle}

